\title{
Meet the New Hormones and Cancer Editorial Team: Gary D. Hammer, Associate Editor
}

Published online: 8 January 2015

(C) Springer Science+Business Media New York 2015

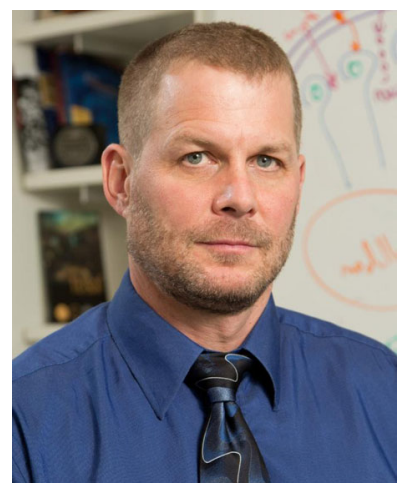

Gary D. Hammer, M.D., Ph.D. is a Professor in the Departments of Internal Medicine (Metabolism, Endocrinology \& Diabetes), Cell \& Developmental Biology, and Molecular \& Integrative Physiology at the University of Michigan. He serves as the Director of the Endocrine Oncology Program in the Comprehensive Cancer Center where he holds the Millie Schembechler Professorship in Adrenal Cancer. He is also the Director of the University's Center for Organogenesis that focuses on organ-specific problems spanning developmental disorders to cancer.

He has served in numerous capacities across the tripartite constituencies of the Endocrine Society including Chair of the Student Affairs Committee, Chair of the Mentoring Task
Force, Basic Science Chair of the Annual Meeting Trainee Day and most recently Council Member at Large and a Society Ambassador to King Edward Memorial Hospital in Mumbai India as part of the 2012 inaugural Endocrine Society Ambassador Exchange Program.

He received the Jerome Conn Award for Outstanding Research in Internal Medicine, the Endocrine Society Edwin B. Astwood Award for Outstanding Research in Endocrinology and is a member of the American Society for Clinical Investigation and Association of American Physicians. He is the editor of three textbooks: "Adrenocortical Carcinoma: Basic Science and Clinical Concepts" (Springer 2011), "Pathophysiology of Disease: An Introduction to Clinical Medicine" (Harper Row, 2014) and "Genetics Steroid Disorders" (Elsevier, 2014).

Research projects in his own laboratory are aimed at elucidating the mechanisms by which growth factor signaling and transcriptional programs initiate adrenal-specific growth and differentiation with an emphasis on dysregulated adrenocortical stem cells in development and cancer. He is a co-founder of the company Atterocor that focuses on therapies for adrenal cancer. Collaborative work with colleagues has led to the development of new national and international therapeutic trials with biological-based therapies for adrenal cancer that target the molecular defects in cancer while sparing normal tissue. 